\title{
Head and neck lymphomas from otolaryngology perspective
}

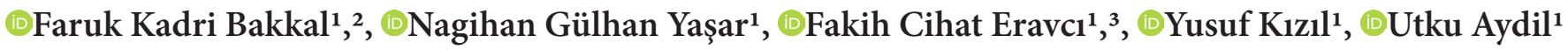 \\ ${ }^{1}$ Gazi University, Faculty of Medicine, Department of Otolaryngology, Ankara, Turkey \\ ${ }^{2}$ Uşak University, Faculty of Medicine, Department of Otolaryngology, Uşak, Turkey \\ ${ }^{3}$ Necmettin Erbakan University, Faculty of Medicine, Department of Otolaryngology, Konya, Turkey
}

Cite this article as: Bakkal FK, Gülhan Yaşar N, Eravcı FC, Kızıl Y, Aydil U. Head and neck lymphomas from otolaryngology perspective. J Health Sci Med 2021; 4(5): 675-679.

\begin{abstract}
Aim: To evaluate the clinical manifestations, histopathologic composition, and demographic characteristics of the lymphomas presented in the head and neck.

Material and Method: Records of subjects who had a diagnosis of lymphoma by an otolaryngology clinic in a tertiary referral hospital between May 2007 and July 2017 were reviewed. Demographic features and data regarding histopathology, radiology, and clinical presentation were evaluated.

Results: A total of 103 lymphomas in the head and neck region, 79 (77\%) nodal lymphoma, and 24 (23\%) extranodal lymphoma, were diagnosed. The initial presentation was solitary lymphadenopathy in 12 (15\%) of the nodal lymphomas but conglomerated or multiple lymphadenopathies in the others. No significant relationship was found between lymph node size and histopathology $(\mathrm{p}=0.144)$. Extranodal lymphomas presented most commonly in tonsils $(\mathrm{n}=8,33 \%)$. Hodgkin lymphoma to non-Hodgkin lymphoma ratio was 0.8 (35/44) among nodal lymphomas. The dominant subgroup of non-Hodgkin lymphomas was diffuse large b-cell lymphoma $(n=18,40 \%)$. All of the Hodgkin lymphomas in our series were classic variant, and the subjects were younger than the non-Hodgkin lymphomas $(\mathrm{z}=-4.803, \mathrm{p}<0.001)$. The histopathology of $46(68 \%)$ of non-Hodgkin lymphomas was aggressive. T/NK-cell NHL was detected in seven subjects (6.8\%). This was the only group with male predominance $(n=5,71 \%)$.

Conclusion: Lymphomas are a large group of malignancies that can present in various clinical forms in the head and neck region. The gender and age of onset of this neoplasm differ by many biological, environmental, and epidemiological factors. Ultrasound findings are crucial in evaluating suspicious lymph nodes. A tissue biopsy is recommended to exclude lymphomas from other neoplasms to make an accurate diagnosis.
\end{abstract}

Keywords: Lymphoma, head and neck, malignancy

\section{INTRODUCTION}

Lymphomas are malignancies originating from the lymphoreticular system. They are the third most common malignancies of the head and neck region after squamous cell cancers and thyroid cancers (1). They should be considered in the differential diagnosis of a patient presenting with a neck mass. But the diagnosis can sometimes be tricky. Although they arise mostly from lymph nodes (NL), they may develop as extranodal lymphoma (ENL) from non-lymph node tissues. According to the histological features, they are divided into two main groups as Hodgkin lymphoma (HL) and Non-Hodgkin lymphoma (NHL). Besides, NHL is classified into two subgroups as b-cell, and t/NK-cell, depending on the cell type in which it develops. However, a large number of subclasses of all subgroups have been identified. Since clinical behavior and treatment plan is different, it is indispensable to determine the subgroup and subclass correctly. The most comprehensive reference in this field is the World Health Organization (WHO) categorization system, based on pathological, clinical, and genetic factors (2).

There is a need for studies that deal with lymphomas in the head and neck region. Therefore, in this study, head and neck lymphomas, which are frequently encountered in otolaryngology practice, were specifically addressed. The 10-year retrospective records of patients diagnosed with lymphoma by an otolaryngology clinic in a tertiary referral center were reviewed, and demographic characteristics, histopathology, radiology, and clinical presentation were evaluated. The fundamental management strategies that should be applied in a subject with lymphoma or possible 
lymphoma in the head and neck region were discussed in the light of the literature. Consequently, it is aimed to convey the ENT perspective on this issue.

\section{MATERIAL AND METHOD}

The study was carried out in full compliance with the Declaration of Helsinki, and the Gazi University Assessment and Evaluation Ethics Sub-Working Group has approved the study (Date: 14.05.2019, Decision No: 91610558-604.01.02-05).

The records of the subjects diagnosed with lymphoma between May 2007 and July 2017 at a tertiary otolaryngology clinic were retrospectively reviewed. Subjects who had a previous diagnosis of lymphoma were excluded. Demographic features and data regarding symptoms, clinical presentation, location of the mass (es), radiological findings, and histopathological type were evaluated.

Lymphomas were classified by reference to the World Health Organization (WHO) system according to their origin and histopathological composition (1). The groups were analyzed comparatively with the demographic characteristics of the patients. The largest diameters of nodal lymphomas and the relationship of lymph node size with histopathology and demographic characteristics were evaluated. Besides, lymphomas were grouped according to their aggressiveness of histopathology, and the relation with other parameters was also evaluated.

Shapiro-Wilk and Kolmogorov-Smirnov tests were used for normality analysis of continuous variables according to the size of the samples and groups. In order to compare the groups, the Mann-WhitneyU test was used for continuous variables, and the $\chi 2$ test was used for categorical variables. IBM Statistical Package for the Social Sciences (SPSS) version 21.0 (Illinois, Chicago) was used for statistical analysis of the data. The results of the study were presented in the light of our clinical practice and literature.

\section{RESULTS}

The population consisted of 103 subjects ( 57 female, 46 male, $\mathrm{F} / \mathrm{M}=1.24$ ). The mean age was 50 years (range $3-85$, $\mathrm{SD}=20.8)$.

Nodal lymphoma (NL) was detected in 79 (77\%) of the subjects, and extranodal lymphoma (ENL) in 24 (23\%).

In the NL group, 43 (54\%) subjects were female, and the mean age of the whole group was 48 years (range 3-85, $\mathrm{SD}=21.6)$.

Among nodal lymphoma subgroups, the mean age of Hodgkin lymphoma (HL) and non-Hodgkin NHL groups were 34 and 59 years, respectively. Subjects with $\mathrm{HL}$ in this series were significantly younger than subjects with NHL $(\mathrm{z}=-4.803, \mathrm{p}<0.001)$ in the NL subgroup. Both HL and NHL subgroups has a slight female dominance ( $\mathrm{F} / \mathrm{M}$ ratios 1.3 and 1.1 , respectively, $\mathrm{p}=0.66$ ).

All of the Hodgkin lymphomas in our series were nodal lymphoma and in classical HL subtype. In 20 (57\%) of the subjects mixed cellular type, in $14(40 \%)$ of the subjects nodular sclerosing type, and in one (3\%) case lymphocyte-rich type were detected.

The nodal NHL group had a large histopathological composition. The most common was diffuse large b-cell lymphoma (DLBCL) in 18 of the subjects $(40 \%)$. The other subtypes are listed in Table 1.

The subjects diagnosed as NL were evaluated by neck ultrasound (US) and colour doppler ultrasound. The location of the lymph nodes in the neck was the deep jugular chain mostly, and the rarest locations were submental and central compartment (Table 2). In 12 $(15 \%)$ of the subjects, the largest diameter of the most prominent lymph node was less than two centimeters $(\mathrm{cm})$. These lymph nodes were solitary and had suspicious sonographic findings. All the other subjects presented with large, multiple, or conglomerated lymph nodes. No significant relationship was found between lymph node size and histopathology (HL or NHL) $(\mathrm{p}=0.144)$.

\section{Table 1. Histopatological subtypes of lymphomas}

\begin{tabular}{|c|c|c|c|}
\hline \multicolumn{2}{|c|}{ Nodal Lymphoma, $\mathbf{n = 7 9}$} & \multirow{2}{*}{\multicolumn{2}{|c|}{$\begin{array}{c}\text { Extranodal Lymphoma, } \mathbf{n}=24 \\
\text { Non-Hodgkin, } n=24\end{array}$}} \\
\hline Hodgkin, $n=35$ & Non-Hodgkin, $\mathrm{n}=44$ & & \\
\hline - Mixt cellular, $\mathrm{n}=20$ & - DLBCL, $\mathrm{n}=18$ & b-cell lymphoma, $n=22$ & t/NK-Cell lymphoma, $n=2$ \\
\hline - Nodular sclerosing, $\mathrm{n}=14$ & - Low grade follicular, $\mathrm{n}=9$ & - DLBC, $n=12$ & - Angioimmunoblastic t-cell, $\mathrm{n}=1$ \\
\hline \multirow[t]{7}{*}{ - Lymphocyte rich, $\mathrm{n}=1$} & - Marginal zone ${ }^{*}, \mathrm{n}=5$ & - Marginal zone $\mathrm{e}^{*}, \mathrm{n}=8$ & - NK-cell, $\mathrm{n}=1$ \\
\hline & - Mantle cell, $n=4$ & - Mantle cell, $n=2$ & \\
\hline & - Angioimmunoblastic t-cell, $n=3$ & & \\
\hline & - Burkitt, $\mathrm{n}=2$ & & \\
\hline & - Peripheric t-cell, $\mathrm{n}=1$ & & \\
\hline & - t-cell lymphoblastic, $\mathrm{n}=1$ & & \\
\hline & - b-cell lymphoblastic, $n=1$ & & \\
\hline
\end{tabular}


Table 2. Primary localization of Nodal lymphomas

\begin{tabular}{|lc|}
\hline Lymph node levels & n (\%) \\
\hline Zone II & $20(25)$ \\
Zone Ib & $18(23)$ \\
Zone IV & $18(23)$ \\
Zone V & $14(18)$ \\
Zone III & $6(7.5)$ \\
Zone Ia & $2(2.5)$ \\
Zone VI & $1(1)$ \\
Total & $79(100)$ \\
\hline
\end{tabular}

Seven patients underwent US-guided fine-needle aspiration biopsy (FNAB) prior to excision; atypical lymphoid cells were observed in three of them, and four were reported as non-diagnostic. The definitive diagnosis was made in all patients after diagnostic excision.

The ENL group consisted of 24 subjects. The mean age was 57 , and $14(58 \%)$ of the subjects were female. The subjects with ENL were older than the subjects with NL (57 \pm 16.2 and $48 \pm 21.6$ respectively, $p=0.078)$. Both groups had a female predominance $(\mathrm{p}=0.736)$. ENL developed most commonly from palatine tonsils $(n=8$, 33\%). The other locations are listed in Table 3.

Table 3. Primary localization of extranodal lymphomas

\begin{tabular}{|lc|}
\hline Extranodal region & $\mathbf{n}(\%)$ \\
\hline Tonsil & $8(33.3)$ \\
Nasopharynx & $5(20.8)$ \\
Parotid gland & $5(20.8)$ \\
Hard palate & $2(8.3)$ \\
Gingiva & $1(4.2)$ \\
Orbita & $1(4.2)$ \\
Lower lip & $1(4.2)$ \\
Trachea & $1(4.2)$ \\
Total & $24(100)$ \\
\hline
\end{tabular}

Twenty-two subjects (91\%) with ENL had b-cell NHL, and only two (9\%) had t/NK-cell lymphoma. The most common histopathologic subtypes were DLBCL (41\%, $\mathrm{n}=9)$ and marginal zone b-cell lymphoma $(36 \%, \mathrm{n}=8)$.

Among all subjects, a sum of seven patients (6.8\%) was diagnosed as $\mathrm{t} / \mathrm{NK}$-cell NHL. This was the only group with male predominance $(n=5,71 \%)$. The mean age in this group was 41 and significantly younger than b-cell NHL (mean age $=60, n=61)(p=0.004)$. The nodal onset rate was $71 \%(n=5)$ in $\mathrm{t} / \mathrm{NK}$ cell lymphomas and was similar to the b-cell lymphomas.

NHL has histopathologically aggressive and indolent types. In our series, 46 (68\%) had aggressive histopathology. There was no significant difference between aggressive and indolent NHL in terms of gender $(\mathrm{p}=0.291)$.

\section{DISCUSSION}

Lymphomas are malignant neoplastic proliferation of the lymphoreticular system. They often arise from lymph nodes, but they can develop from any tissue with lymph flow. Enlarged, painless lymphadenopathy (LAP) is mostly the main clinical symptom. On physical examination, enlarged nodes in lymphoma are rubbery and mobile (3). Approximately $80 \%$ of HL and $10-20 \%$ of NHL cases manifest as an enlarged lymph node within the head and neck region (4). In 20-30\% of these subjects, lymphomas derive from extranodal tissues (5). In our study, $24 \%$ of the lymphomas derived from extranodal tissues, which is similar to the literature.

In previous studies, the most common ENL origins were reported as the Waldeyer's ring (6) or the sinonasal region $(7,8)$. In our study, the most common location of masses related to NHL was palatine tonsil (33\%), followed by nasopharynx, parotid gland, and hard palate (Table 3). Bilateral tonsillar involvement was seen in one subject and, in all other cases, presented with unilateral tonsil hypertrophy. Diagnostic tonsillectomy should be considered particularly in unilateral tonsillar hypertropy (8). Sinonasal NHL has been reported more in Asian countries than in western countries (9). However, ENL can develop from many other tissues in the head and neck. Because they can mimic squamous cell cancers of the head and neck, a deep tissue biopsy should be performed and confirmed for a definite diagnosis before any radical surgery (3).

Nodal lymphomas often present with large, multiple, and conglomerated lymphadenopathy. There is no difficulty in this group about decision making for diagnostic excision. On the other hand, $15 \%$ of the subjects with NL present with small solitary lymph nodes less than two centimeter in the largest diameter. In these subjects, the clinical findings may be masked and suspicious nodes can be overlooked on physical examination. The pathological indicators on ultrasound (US) and colour Doppler US (e.g., spherical lymph nodes with a diameter $>5 \mathrm{~mm}$, loss of hilar architecture, presence of intranodal necrosis and calcification, matting, increased hilar and peripheral vascularization) should suggest lymphoma and require excision of the lymph node for further evaluation (10).

Fine needle aspiration biopsy (FNAB) may provide limited data in the differential diagnosis and remains inadequate in most of the situations (11). In our study, FNAB was performed in seven of the subjects presented with small suspicious lymph nodes, but atypical lymphoid cells were detected in only three of them. In the other four, results of the cytological examination were nondiagnostic. A definitive diagnosis was made by excisional lymph node biopsy in all seven cases. Although there 
have been reports suggesting tissue diagnosis by core biopsy in recent years, the lymph node excision remains the gold standard in lymphoma (12-14).

Lymph nodes related to NL were rarely encountered in the midline lymph node groups such as level Ia and VI. Only three of the subjects in our series developed LN from the central neck zones. This is probably related to a lower number of total lymph nodes located within these zones compared to the others.

The relationship between lymphoma and gender is heterogeneous in the previous studies (15). This difference should be evaluated with various genetic, social, and environmental characteristics $(6,15,16)$. The exact correlation between the frequency of lymphoma and gender has not been shown. In our study, a slight female predominance was present, but the only exception was t/NK-cell NHL, which was more common in males.

Age distribution of lymphoma varies according to geographical regions. In general, studies published from the western countries have higher mean ages, while the reports from Asian countries have reported earlier mean ages $(7,16)$. In our series, the mean age in the NL and ENL groups was 48 and 57, respectively $(\mathrm{p}=0.078)$. The mean age of the HL group in our series was 34 , the youngest in our study, and younger than nodal NHL $(p=0.141)$. The incidence of HL increase in the third decade continues to decrease in the following years, but usually increases again after 45 and makes a bimodal peak (17). In our study, only a single peak was detected in the third decade (Figure). In addition, the mean age of $\mathrm{t} / \mathrm{NK}$-cell NHL was significantly lower than the b-cell NHL. In contrast to our series, t/NKcell lymphomas reported older (around the age of 60) in large cohorts from the United States. The age of onset of this rare neoplasm is associated with many biological, environmental, and epidemiological factors (18).

Unlike developed countries where the nodular sclerosing type $\mathrm{HL}$ is predominant, the mixed cellular type was more common in our study, which is similar to the reports from other developing countries. Mixed cellular type is known as a more aggressive subtype than nodular sclerosing type (19). Viral agents (e.g., EpsteinBarr virus) are blamed for the aetiology of mixed cellular type, and its higher incidence in undeveloped or developing countries may be due to the higher contamination rates (20). All HLs were nodal in our series, and extranodal HL was not detected, which is comparable with previous reports (3).

The most common histopathological type of all cases in our study (both NL and ENL) was NHL, and the most common subgroup was DLBCL. NHL is reviewed in two forms as rapid proliferating (aggressive) and slow-acting (indolent) lymphomas. DLBCL, Burkitt lymphoma, mantle cell lymphoma, most peripheric t-cell lymphomas, both t-cell and b-cell lymphoblastic lymphomas, human immunodeficiency virus (HIV) related lymphomas and transformed lymphomas have aggressive behavior (21). Indolent lymphomas are lowgrade follicular lymphoma, marginal zone lymphoma, plasmacytoma, and low-grade b-cell lymphoma of mucosa-associated lymphoid tissue (MALT lymphoma) (22). Several NHL subtypes are classified as aggressive. In accordance with the literature, aggressive histopathology was found to be $68 \%$ predominant in our study (23).

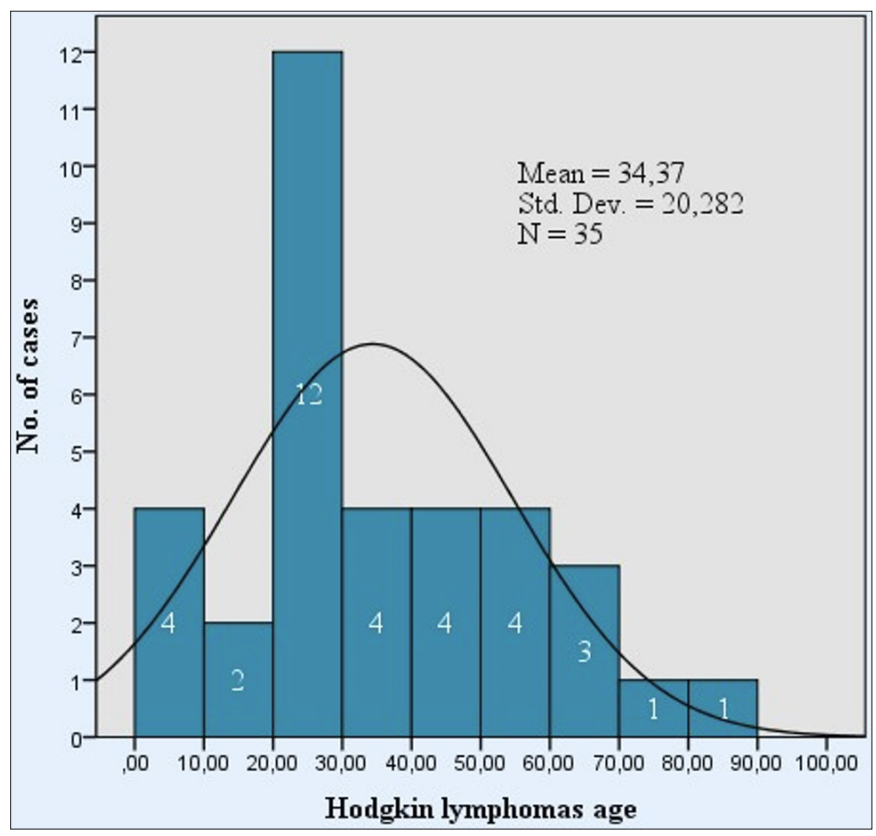

Figure. Histogram demonstrating a single peak in the third decade of the hodgkin lymphoma group.

\section{CONCLUSION}

Lymphomas are a large group of malignancies that can present in various clinical forms in the head and neck region. Lymph nodes may not always enlarge in lymphoma. However, conglomerated lymphadenopathy may not always be present. According to our results, 15\% of nodal lymphomas present with a solitary lymph node small than two centimeters in the largest dimension. The US has a crucial role to evaluate the lymph nodes in such cases.

NHLs can develop from multifarious extranodal tissues of the head and neck and can mimic other common head and neck malignancies like squamous cell carcinomas. In this respect, it should be considered in the differential diagnosis of head and neck tumors. A tissue biopsy is recommended to exclude lymphomas, and other neoplasms to avoid unnecessary surgeries in such situations. 


\section{ETHICAL DECLARATIONS}

Ethics Committee Approval: Gazi University Assessment and Evaluation Ethics Sub-Working Group has approved the study (Date: 14.05.2019, Decision No: 91610558-604.01.02-05).

Informed Consent: Because the study was designed retrospectively, no written informed consent form was obtained from patients.

Referee Evaluation Process: Externally peer-reviewed.

Conflict of Interest Statement: The authors have no conflicts of interest to declare.

Financial Disclosure: The authors declared that this study has received no financial support.

Author Contributions: All of the authors declare that they have all participated in the design, execution, and analysis of the paper, and that they have approved the final version.

\section{REFERENCES}

1. Cooper JS, Porter K, Mallin K, et al. National Cancer Database report on cancer of the head and neck: 10-year update. Head Neck 2009; 31: 748-58.

2. Swerdlow SH, Campo E, Pileri SA, et al. The 2016 revision of the World Health Organization classification of lymphoid neoplasms. Blood 2016; 127: 2375-90.

3. Zapater E, Bagán J, Carbonell F, Basterra J. Malignant lymphoma of the head and neck. Oral Dis 2010; 16: 119-28.

4. Weber AL, Rahemtullah A, Ferry JA. Hodgkin and non-Hodgkin lymphoma of the head and neck: clinical, pathologic, and imaging evaluation. Neuroimaging Clin N Am 2003; 13: 371-92.

5. Urquhart A, Berg R. Hodgkin's and non-Hodgkin's lymphoma of the head and neck. Laryngoscope 2001; 111: 1565-9.

6. Beasley M. Lymphoma of the thyroid and head and neck. Clin Oncol 2012; 24: 345-51.

7. Hanna E, Wanamaker J, Adelstein D, Tubbs R, Lavertu P. Extranodal lymphomas of the head and neck: a 20-year experience. Arch Otolaryngol Head Neck Surg 1997; 123: 1318-23.

8. Oluwasanmi AF, Wood SJ, Baldwin DL, Sipaul F. Malignancy in asymmetrical but otherwise normal palatine tonsils. Ear Nose Throat J 2006; 85: 661-3.

9. Woo J-S, Kim JM, Lee S, Chae S, Hwang S, Lee HM. Clinical analysis of extranodal non-Hodgkin's lymphoma in the sinonasal tract. Eur ArchOtorhinolaryngol 2004; 261: 197-201.

10. Ahuja AT, Ying M, Ho SY, et al. Ultrasound of malignant cervical lymph nodes. Cancer Imaging 2008; 8: 48-56.

11. Burke C, Thomas R, Inglis C, et al. Ultrasound-guided core biopsy in the diagnosis of lymphoma of the head and neck. A 9 year experience. Brit J Radiol 2011; 84: 727-32.

12. Nyquist GG, Tom WD, Mui S. Automatic core needle biopsy: a diagnostic option for head and neck masses. Arch Otolaryngol Head Neck Surg 2008; 134: 184-9.

13. Allin D, David S, Jacob A, Mir N, Giles A, Gibbins N. Use of core biopsy in diagnosing cervical lymphadenopathy: a viable alternative to surgical excisional biopsy of lymph nodes? Ann R Coll Surg Eng 2017; 99: 242-4.

14. Houcine Y, Romdhane E, Blel A, et al. Evaluation of fine needle aspiration cytology in the diagnosis of cervical lymph node lymphomas. J Craniomaxillofac Surg 2018; 46: 1117-20.
15. Etemad-Moghadam S, Tirgary F, Keshavarz S, Alaeddini M. Head and neck non-Hodgkin's lymphoma: a 20-year demographic study of 381 cases. Int J Oral Max Surg 2010; 39: 869-72.

16. Roman E, Smith A. Epidemiology of lymphomas. Histopathology 2011; 58: 4-14.

17. Alexander FE, Ricketts TJ, McKinney PA, Cartwright RA. Community lifestyle characteristics and incidence of Hodgkin's disease in young people. Int J Cancer 1991; 48: 10-4.

18. Phan A, Veldman R, Lechowicz MJ. T-cell lymphoma epidemiology: the known and unknown. Curr Hematol Malig Rep 2016; 11: 492-503.

19. Agostinelli C, Pileri S. Pathobiology of hodgkin lymphoma. Mediterr J Hematol I 2014; 6: e2014040.

20. Glaser SL, Lin RJ, Stewart SL, et al. Epstein-Barr virus-associated Hodgkin's disease: epidemiologic characteristics in international data. Int J Cancer 1997; 70: 375-82.

21. Said JW. Aggressive B-cell lymphomas: how many categories do we need? Mod Pathol 2013; 26: S42-S56.

22.Fisher RI, Dahlberg S, Nathwani BN, Banks PM, Miller TP, Grogan TM. A clinical analysis of two indolent lymphoma entities: mantle cell lymphoma and marginal zone lymphoma (including the mucosa-associated lymphoid tissue and monocytoid B-cell subcategories): a Southwest Oncology Group study. Blood 1995; 85: 1075-82.

23. Al-Hamadani M, Habermann TM, Cerhan JR, Macon WR, Maurer MJ, Go RS. Non-H odgkin lymphoma subtype distribution, geodemographic patterns, and survival in the US: A longitudinal analysis of the National Cancer Data Base from 1998 to 2011. Am J Hematol 2015; 90: 790-5. 